\title{
A Numerical Study on High Velocity Impact Behavior of Titanium Based Fiber Metal Laminates
}

\author{
Gin Boay Chai ${ }^{1, * \mathbb{D}}$, Periyasamy Manikandan ${ }^{1}$ and $\mathrm{Xin} \mathrm{Li}^{1,2}$ \\ 1 School of Mechanical and Aerospace Engineering, Nanyang Technological University, \\ Singapore 639798, Singapore; manikandanP@ntu.edu.sg (P.M.); \\ lixin@nju.edu.cn or lixin1986@tyut.edu.cn (X.L.) \\ 2 National Laboratory of Solid State Microstructures \& Department of Materials Science and Engineering, \\ Nanjing University, Nanjing 210093, China \\ * Correspondence: mgbchai@ntu.edu.sg
}

Received: 13 August 2018; Accepted: 16 October 2018; Published: 22 October 2018

check for updates

\begin{abstract}
The present paper gives details of the structural response of titanium-based fiber metal laminates (TFML) subjected to high velocity impact. Dynamic perforation behavior of two different sample configurations, TFML-2/1 and 3/2 are presented. The behavior of the metal and composite layer is defined using two independent appropriate constitutive material models. Both experimental and numerically predicted residual velocity follows the Recht-Ipson model variation with impact velocity. Being larger in thickness, residual velocity, peak contact force and total energy absorbed were found to be larger for TFML-3/2 than 2/1. However, the contact duration was rather insignificantly affected. Having similar metal volume fraction (MVF), energy dissipated by means of plastic deformation of metal layers was found to be constant for both TFML configurations that were considered. The axisymmetric loading, boundary conditions and having balanced material property distribution along the principle axes resulted in doubly symmetric damage surfaces, both layer-wise and overall. The developed finite element (FE) model adequately simulated the contact behavior and all of the experimentally realized damage modes in the metal and composite layers and confirmed its reliability. Having limited experimental information, the obtained numerical information allows one to briefly understand the dynamic perforation behavior of TFML laminates.
\end{abstract}

Keywords: fiber metal laminates; finite element model; multi continuum theory; ballistic impact; projectile velocity

\section{Introduction}

Over the past two decades, composite material application has been widespread to all forms of structures, ranging from uncritical secondary components to highly critical primary load carrying components. However, the brittle nature of composites and, consequently, their predisposition of fracture led to the resultant structures becoming highly sensitive and prone to sudden localized dynamic loads like high velocity and ballistic impact events e.g., bird strike in aviation, vehicle collision in automobile, armor plate of military personnel, etc. So far, many hybridization techniques have been investigated to improve the ballistic resistance of composite materials, such as the development of ceramic faced composite laminates as armor shields [1], the invention of high strength light weight fibres like ultra high molecular weight polyethylene fibres (UHMWPE) [2] and the creation of multifunctional hybrids by interlaying brittle and ductile material layers with appropriate stack arrangement.

Fibre metal laminate (FML) is one such multifunctional hybrid material that combines metal and composite layers that exhibit enhanced energy absorption characteristics, excellent impact resistance 
and post impact damage tolerance compared to the structure being made of either metal or composite alone [3]. Although FML was initially developed to improve fatigue properties, it was later found that it is also good as an impact resistant material compared to monolithic aluminum alloy of the same aerial density [4]. Soon after the exploration of the successful FML concept in 1980, Vogelesang, Paalvast and Verbruggen of Delft University developed a specific FML variant for enhanced ballistic resistance, constituting Kevlar fabric layer between aluminium metal layers and covered by ceramic tiles [3]. As time progressed, many FML variants with different types of metal and composite constituents have been explored and investigated for ballistic reliability. The impact behavior of laminated materials including FML are majorly attributed by impact velocity regimes. In-plane stress governed by bending/membrane waves dominate the low velocity impact (LVI), while transverse shear stress governed by transverse shear waves dominate the high velocity ballistic impact (HVI) [5]. Hoo Fatt et al. [6] investigated the ballistic resistance of glass fibre based FML variant GLARE (Glass fibre reinforced aluminium laminates). Delamination along the metal-composite interface was found to be more dominant during ballistic impact, which greatly reduces the bending stiffness of FML laminate and causes the incorporated metal layer to deform more by membrane stretching. It was shown that deformation due to bending and membrane stretching of the layers accounted for nearly $92 \%$ of the total absorbed energy, and also showed that thinner FML panels absorb more energy than thicker counterparts. Compared to the equivalent mass of aluminium alloy, the ballistic limit of GLARE FML was noticed to be $15 \%$ larger. Cantwell et al. [7-10] postulated a new family of thermoplastic-based fibre-metal laminates that were fabricated using aluminium alloy and E-glass/polypropylene (GFPP) for better ballistic resistance properties. A series of experimental and numerical studies confirmed their hypothesis that perforation resistance of thermoplastic-based FML was superior to thermoset (epoxy) based FML.

Cortés [11,12] extended the thermoplastic concept to titanium-based fiber metal laminate (TFML) through replacing aluminum metal layer to titanium. Including excellent strength-to-weight ratio, low density and better corrosion resistance, the lower thermal expansion coefficient of titanium alloy [13] in combination with carbon fiber-reinforced polymer extend the application of TFML to high temperature environments. A recent experimental study explored the role of different fiber reinforcements on the ballistic response of TFML [14]. The incorporation of high flexible, high strength and low interlaminar shear resistant UHMPWE fiber layer was found to increase the ballistic limit by up to $30 \%$ more than the TFML of the same aerial weight made from carbon fiber reinforced polymer (CFRP) layer.

Unlike quasi-static indentation and low velocity impact study, the information attributed from ballistic experiments is fairly scarce. The sudden abrupt ballistic event limits the real-time quantitative output extraction necessitate high-speed complex device to monitor the projectile/target behavior and often makes it difficult to achieve good repeatability. Moreover, extracted information is primarily based on projectile characteristics and, apart from post mortem study, no other pertinent information was ascertained about target behavior. These limitations gave researchers impetus to perform virtual ballistic simulations by developing a reliable finite element (FE) model to characterize the whole behaviour through detailed quantitative information.

Modelling aspects governing the numerical simulation of metal and composite structures subjected to ballistic perforation were found in the literature [15-21]. There has been considerable work carried out on numerical response of FML too. Liaw et al. [22,23] investigated the stacking sequence and thickness influence of GLARE 5 FML laminates to ballistic impact load using LS-DYNA finite element code. Johnson Cook (JC) criteria and chang-chang damage criteria was used to model aluminium layer plasticity and GFRP layer failure modes. Thermal effects and damage of the aluminum layer were ignored in the developed model. It was found that cross ply composite reinforcements in FML offered the highest contact resistance and also dissipated more energy compared to other stacking reinforcements. With an increase in FML thickness, the ballistic limit velocity was found to vary quadratically. Soutis et al. [24] utilized a similar FE model along with the inclusion of the metal-composite interface (MCI) de-bonding definition to test the durability of GLARE under blast 
load. Vo et al. [10] studied the influence of different aluminium alloys in thermoplastic-based FMLs using ABAQSU/Explicit commercial FE software and reported that FML with higher yield modulus and strength (Al 7075-T6) offered better blast resistance among the other tested candidates. JC criteria for metal layer plasticity and damage, Hashin 3D failure criteria and strain rate effect for woven composite layer and the introduction of cohesive elements between metal-composite interface (MCI) are the notable aspects. Since Hashin failure criteria is applicable for unidirectional (UD) lamina, the woven composite lamina was modelled by defining independent material orientation by [0/90] UD pair. Sitnikova et al. [25] improved the composite failure criteria with a set of quadratic based tension-shear and compressive failure criteria for weft and warp fibre directions of woven lamina in their FE model. Good agreements with published experimental damage shapes had proven the ability of a user-defined woven fabric failure model. Failure theories based on multi-continuum theory (MCT) had shown excellent agreement to predict constituent level (warp, weft fibers and matrix) damage modes for plain weave woven composite materials [26,27].

Kotzakolios et al. [28] extended the numerical study of ballistic loading to complex real structures. An attempt was made to investigate the reliability of GLARE FML for aircraft fuselage structure using LS-DYNA finite element code. In spite of certain limitations, the study confirmed that FEM would be an economic tool that would be able to optimize the initial considered design.

Like GLARE FML, in-depth numerical investigation about dynamic blast and the perforation behavior of TFML is not available in the literature. Nakatani et al. [29] numerically investigated the low velocity behavior of TFML laminate. The material model that was used to model TFML was JC plasticity for titanium and 2D Hashin failure criteria for the composite layer. Being compatible with carbon/graphite fibers and exhibiting excellent ballistic resistance (compared to aluminium and steel of the same aerial weight), the complete understanding of Titanium combined with carbon fiber based FML may be viable to applications like armors, impact critical high temperature shells, etc.

In this motive, this article investigates the dynamic perforation behavior caused by ballistic impact loading of TFML samples made of different stacking arrangement through finite element simulation. The fidelity of obtained numerical results were compared with residual velocity of projectile and post-damage experimental results [14]. Some insight details, such as the contact force history, energy dissipation mode, damage surface of each material layers and their constituents, which are feasible solely by numerical simulation, are presented.

\section{Materials}

The TFML samples that were investigated were fabricated from a Ti-6Al-4V Titanium alloy and plain weave carbon fabric (HexForce ${ }^{\mathrm{TM}} 282,3 \mathrm{~K}$, supplied by Hexcel Corporation, Stamford, CT, USA). The thickness and areal density of the titanium sheets were $0.5 \mathrm{~mm}$ and $0.226 \mathrm{~g} / \mathrm{cm}^{2}$, respectively; whereas, the areal density of plain-woven carbon fabric was $197 \mathrm{~g} / \mathrm{m}^{2}$. Epoxy matrix resin (Eploam 5015/5015 supplied by Axson Technologies, Shanghai, China) was used to reinforce carbon fabrics and to bond them with the titanium layer by the hand lay-up process. In order to enhance the bonding between Ti sheet and CFRP, the titanium sheets were annealed in a furnace at $500{ }^{\circ} \mathrm{C}$ for $8 \mathrm{~h}$ to form an $8 \mu \mathrm{m}$ oxide layer [14]. Four plies of carbon fabric were placed between two titanium sheets, and the titanium sheets were aligned such that their rolling directions were parallel, as shown in Figure 1a. A vacuum bagging process was used to absorb excess resin and to promote curing of the epoxy. The samples were cured at room temperature for $24 \mathrm{~h}$ and were then placed in an oven for post-curing at $80^{\circ} \mathrm{C}$ for $16 \mathrm{~h}$. The fabricated samples were cut into $100 \mathrm{~mm} \times 100 \mathrm{~mm}$ squares using water-jet cutting.

Two TFML sample configurations were investigated, $2 / 1$ and $3 / 2$, where fraction $A / B, A$ and $B$ represent the number of metal and composite layers that were stacked to fabricate TFML. In the finite element model, the panel thickness was considered as the average value of the samples that were investigated in the experimental study. The metal volume fraction (MVF) that was stated by the ratio of volume of metal layer to volume of TFML was around 0.5 for both $2 / 1$ and $3 / 2$ panels, regardless of 
their distinct stacking arrangement and panel thickness. The configuration and details of the TFML panels that were investigated in this article are given in Table 1.
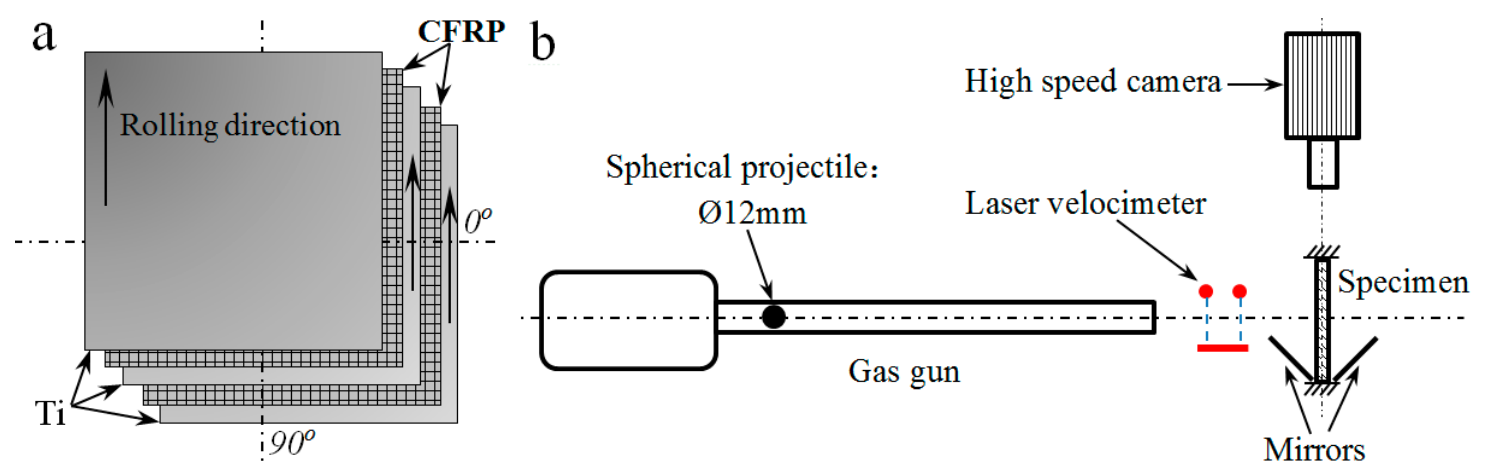

Figure 1. Ballistic impact experiment (a) Illustration of $3 / 2$ fibre metal laminate (FML), and (b) Experimental set up.

Table 1. Configurations of the titanium-based fibre metal laminate (TFML) Panel.

\begin{tabular}{cccccccc}
\hline \multirow{2}{*}{ Nomenclature } & \multirow{2}{*}{ Stacking Sequence } & \multicolumn{4}{c}{ Thickness $(\mathbf{m m})$} & \multicolumn{3}{c}{ Areal Density $\left(\mathrm{g} / \mathbf{c m}^{2}\right)$} & \multirow{2}{*}{ MVF } \\
\cline { 3 - 6 } & & Ti & CF & TFML & EXP & NUM & \\
\hline TFML 2/1 & $\mathrm{Ti} / \mathrm{CF} / \mathrm{Ti}$ & 1 & 0.85 & 1.85 & 0.565 & 0.572 & 0.54 \\
TFML 3/2 & $\mathrm{Ti} / \mathrm{CF} / \mathrm{Ti} / \mathrm{CF} / \mathrm{Ti}$ & 1.5 & 1.7 & 3.2 & 0.899 & 0.914 & 0.47 \\
\hline
\end{tabular}

\section{Overview of the Experimental Study}

The test set-up consisted of a gas gun, laser velocimeter, high-speed camera and specimen clamps, as shown in Figure 1. TFML specimens were clamped along their edges between two steel plates with circular openings; this exposed a circular target area $76 \mathrm{~mm}$ in diameter. A $12 \mathrm{~mm}$ diameter, $7 \mathrm{~g}$ steel sphere was launched by the gas gun to impact the specimens at the center at normal incidence. The impact velocity $\left(V_{i}\right)$ was derived by measuring the time taken by the projectile to cut the two laser beams in its trajectory, and the residual velocity $\left(V_{r}\right)$ of the projectile was measured through a high-speed camera according to the following equations:

$$
\begin{aligned}
& V_{i}=\frac{\Delta S_{1}}{\Delta t_{1}} \\
& V_{r}=\frac{\Delta S_{2}}{\Delta t_{2}}
\end{aligned}
$$

where $\Delta S_{1}$ and $\Delta S_{2}$ are the distance between the two laser beams and two mirrors, respectively and $\Delta t_{1}$, and $\Delta t_{2}$ are the respective time magnitude that were taken by the projectile. It should be noticed that the measurement difference for $V_{i}$ impact velocity between the laser velocimeter and high-speed camera was less than $2 \%$, thus, the residual velocity that was measured by the high-speed camera is credible. The ballistic velocity limit $\left(V_{b}\right)$, which is defined as the lowest impact velocity required for complete perforation, was found for each TFML sample by impacting the sample at different velocities ranging from no perforation to complete perforation. Detailed information about the experimental test methodology can be found in reference [14].

\section{Numerical Simulation}

The ballistic impact experiment that was described in the prior section was simulated using the commercial explicit finite element platform, ABAQUS/Explicit. The main objective of the numerical analyses was to develop a model that simulated the experimentally observed failure modes and to understand the dynamic behavior of the hybrid TFML target in detail. 


\subsection{Constitutive Material Model}

Undamaged and damaged response of metal and fibre reinforced composite layer was simulated by defining two separate non-interactive constitutive material models. The hydrodynamic behavior of the metal layers due to the sudden shock wave fashion of the stress propagation that was caused by the high velocity ballistic impact was modelled using the Mie-Gruneisen equation of state (EOS) model [17]. Mechanical behavior of metal was defined using the linear isotropic elasticity definition, and the subsequent plastic behavior follows the Johnson-Cook (JC) based plasticity model. Correspondingly, the Johnson Cook dynamic damage failure criteria modelled the failure response of the metal layers, which accounts not only for the strain rate effects, however also for the temperature influence on damage initiation, which is important for sudden dynamic loading cases like ballistic impact [30].

For the composite layer, the mutually perpendicular directional dependent elastic behavior was defined as orthotropic property. Distinct failure modes that were attributed by the fibre and matrix components of the composite layers were modelled using the multi-continuum based mode wise failure model that was provided by the Autodesk simulation composite analysis, 2015 [31]. Replicating sudden catastrophic fracture nucleation, zero fracture energy based propagation criterion was used to model instantaneous damage evolution on both the metal and composite layer. Material data that was used to define the titanium metal and CFRP composite material models are listed in Tables 2 and 3, respectively. A detailed mathematical description about these constitutive material models is provided in Appendices A and B.

Table 2. Titanium Ti-6Al-4V material properties.

\begin{tabular}{|c|c|c|c|c|c|c|}
\hline \multicolumn{7}{|c|}{ Input Parameters for the Mie-Gruneisen Equation of State (EOS) Model [32] } \\
\hline $\begin{array}{l}\text { Reference } \\
\text { Density } \\
\left(\mathrm{kg} / \mathrm{m}^{3}\right)\end{array}$ & $\begin{array}{l}\text { Gruneisen } \\
\text { Coeffiecient } \\
\left(\Gamma_{0}\right)\end{array}$ & $\begin{array}{c}\text { Parameters } \\
\left(c_{0}\right)\end{array}$ & $\begin{array}{l}\text { Parameter } \\
\text { (s) }\end{array}$ & $\begin{array}{c}\text { Reference } \\
\text { Temperature } \\
\text { (K) }\end{array}$ & Speci & Heat $(\mathrm{J} / \mathrm{kg} \mathrm{K})$ \\
\hline 4418 & 1.25 & 4973 & 1.111 & 293.2 & & 670 \\
\hline \multicolumn{7}{|c|}{ Input Parameters for the Johnson-Cook Plasticity Model [30] } \\
\hline $\mathrm{A}(\mathrm{MPa})$ & B (MPa) & $\mathbf{N}$ & $\theta_{\text {melt }}(K)$ & $\theta_{\text {transition }}(\mathbf{K})$ & $\mathbf{m}$ & $\varepsilon_{0}(1 / s)$ \\
\hline 1000 & 331 & 0.34 & 1903.15 & 293.2 & 0.8 & $0.012 \quad 1$ \\
\hline \multicolumn{7}{|c|}{ Input Parameters for the Johnson-Cook Dynamic Failure Model [30] } \\
\hline $\mathrm{d}_{1}$ & $\mathrm{~d}_{2}$ & $d_{3}$ & & $\mathrm{~d}_{4}$ & & $\mathrm{~d}_{5}$ \\
\hline-0.09 & 0.2 & 0.5 & & 0.014 & & 3.87 \\
\hline
\end{tabular}

Table 3. Plain weave carbon fiber reinforced polymer (CFRP) material properties.

\begin{tabular}{|c|c|c|}
\hline \multicolumn{3}{|c|}{ Young's modulus (GPa) } \\
\hline${ }^{*} \mathrm{E}_{11}=69.3$ & $E_{22}=E_{11}=69.3$ & $\mathrm{E}_{33}=8.79$ \\
\hline \multicolumn{3}{|c|}{ Poisson's ratio } \\
\hline$v_{12}=0.07$ & $v_{13}=0.367$ & $v_{23}=0.367$ \\
\hline \multicolumn{3}{|c|}{ Shear Modulus (GPa) } \\
\hline${ }^{*} \mathrm{G}_{12}=4.80$ & $\mathrm{G}_{13}=3.04$ & $\mathrm{G}_{23}=3.04$ \\
\hline \multicolumn{3}{|c|}{ Tensile failure strength (MPa) } \\
\hline & \multicolumn{2}{|c|}{$X_{2 t}=X_{1 t}=488$} \\
\hline \multicolumn{3}{|c|}{ Compressive failure strength (MPa) } \\
\hline & \multicolumn{2}{|c|}{$X_{2 c}=460$} \\
\hline \multicolumn{3}{|c|}{ Shear strength (MPa) } \\
\hline & \multicolumn{2}{|c|}{$\mathrm{S}_{13}=119$} \\
\hline
\end{tabular}

\footnotetext{
* From the respective standard experiment. Other values are assumed from [33].
} 


\subsection{Initial and Boundary Conditions}

The TFML plate was perfectly clamped along its circumferential perimeter by constraining both translational and rotational degrees of freedom using ENCASTRE boundary type. Contact interactions between the steel impactor and the TFML target were introduced using general contact algorithm with a frictionless assumption between the two mating surfaces. Such an assumption is greatly valid since sudden low mass and large energy impact situations allow the target panel to undergo large sliding deformations and relative displacement between the mating surfaces that are not predominant.

The interface region between the titanium and CFRP composite layers are assumed to be perfectly bonded using the tie constraint definition for the following two reasons. First, in contrast to low velocity impact, the interface influence on damage initiation to the adjacent layers was not significant for ballistic impact. This is because the stress waves that originated under the contact point travelled at a very high velocity and the time to surpass the thin interface and reach the bottom most material layer of the laminate is extremely small, which eventually resulted in highly localized perforated damage with not much disturbance along the interface region. Second, the amount of energy dissipated by the thin interface region is negligibly small compared to the overall absorbed energy of the TFML panel. Thus, the resultant characteristic curves and damage locus shows rather significant variation for the samples, irrespective of the degree of interface adhesion [34].

To apply the known incident kinetic energy to the target at time $t=0$, constant mass and predefined velocity magnitude are defined via the reference point coupled to the steel projectile. The resultant contact force history induced over the projectile surface is retrieved through the reference point using the inbuilt total contact force history output variable CFT.

\subsection{Element and Mesh Details}

Both titanium and CFRP composite layers were discretized using three-dimensional reduced integrated solid element (C3D8R). This element type includes all six components of induced stresses which are dominant for the case of high energy out-of-plane ballistic impact loading. The density of steel is comparatively two times larger than the density of the impact face titanium layer of the TFML panel. No distortion in shape or damage was noticed on the steel projectile for all of the impact velocity range in the experimental study. Thus, the steel projectile is defined as rigid body and discretized using three-dimensional rigid solid element (R3D8R). This assumption greatly saves the computational cost and time of each simulation.

Reduced integrated elements (C3D8R) are tolerant to shape distortion, however it often tends to be excessively flexible and suffers a peculiar numerical difficulty called the hourglassing effect, which causes a zero-energy mode deformation response. In the current simulation, enhanced hourglass stiffness is set to avoid such a non-physical response [35]. Mesh distribution is defined in a manner such that fine mesh was introduced around the impact region where strain gradients are much higher, and variably coarse meshes are employed near the boundary. Each material layer had four elements through the thickness to effectively model the bending deformation of the TFML panel. Figure 2 presents the geometry and boundary conditions of the finite element model that was used in the current study. 


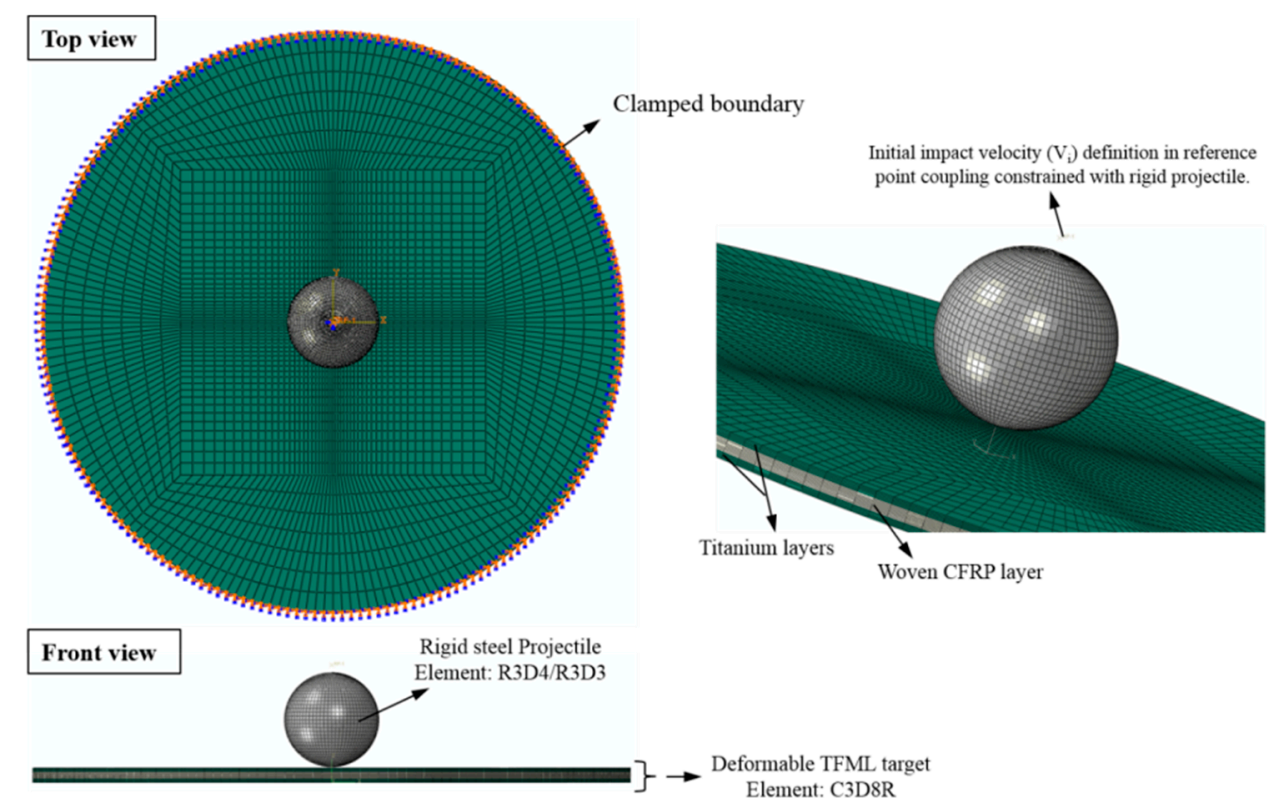

Figure 2. Finite element model and geometry.

\section{Results and Discussion}

Numerical predictions were validated with experimental findings by comparing the residual velocity of the projectile. Following that, parameters like projectile kinetic energy, amount of energy transfer, contact force and time variation, overall energy absorbed and energy absorbed which correspond to plastic deformation of the titanium layers of TFML panels were investigated. Damage progression and resultant damage shapes of each material layer of the TFML target which were predicted by the numerical model are presented in comparison with the experimental observations.

\subsection{Projectile Velocity $(V p)$}

Incident impact velocity $\left(V_{i}\right)$ of the projectile is the primary stimuli which determines the nature of impact deformation and the level of catastrophe on the target. Based on the magnitude of projectile velocity at the end of the contact event $\left(V_{p}\right)$, it can be stated as three distinct forms.

1. Rebound velocity $\left(V_{r b}\right)$ : For impact velocity smaller than the ballistic velocity $\left(V_{i}<V_{b}\right)$, the incident kinetic energy $\left(E_{k}^{p}\right)$ of the projectile is not enough to perforate the target and the projectile rebound back after it transforms all of its energy to the target. In this case, the velocity of the projectile $\left(V_{p}\right)$ monotonically decreases to the rebound velocity by passing through zero $\left(V_{r b}<0\right)$ at which the projectile regains kinetic energy through the elastic rebound of the target and bounces back in the opposite direction.

2. Ballistic velocity $\left(V_{b}\right)$ : At impact velocity equals the ballistic velocity $\left(V_{i}=V_{b}\right)$, the kinetic energy of the projectile $\left(E_{k}^{p}\right)$ is just enough to completely perforate the target and the velocity of the projectile becomes zero $\left(V_{p}=0\right)$ at the end of the contact event.

3. Residual velocity $\left(V_{r}\right)$ : For impact velocity larger than the ballistic velocity $\left(V_{i}>V_{b}\right)$, only a small fraction of the kinetic energy of the projectile $\left(E_{k}^{p}\right)$ is enough to perforate the target and the projectile continues its travel through the target just like a rigid body at a constant residual velocity $\left(V_{p}=V_{r}\right)$.

A plot of the residual impact velocity as a function of impact velocity obtained from experimental tests and numerical simulations for TFML $2 / 1$ and $3 / 2$ samples is illustrated in Figure 3. For TFML $2 / 1$, ballistic velocity, $V_{b}$ is observed at $151 \mathrm{~m} / \mathrm{s}$ and $102 \mathrm{~m} / \mathrm{s}$, while that of TFML $3 / 2, V_{b}$ is $200 \mathrm{~m} / \mathrm{s}$ and $140 \mathrm{~m} / \mathrm{s}$ for the experimental the and numerical result, respectively. The variation of residual 
impact velocity, $V_{r}$ that was obtained from both predictions follows the Recht-Ipson model given by [36],

$$
V_{r}=\alpha\left(V_{i}^{\beta}-V_{b}^{\beta}\right)^{1 / \beta}
$$

Table 4 lists the residual velocity prediction from experimental, numerical and Recht-Ipson model parameters by knowing the numerical $V_{b}$.

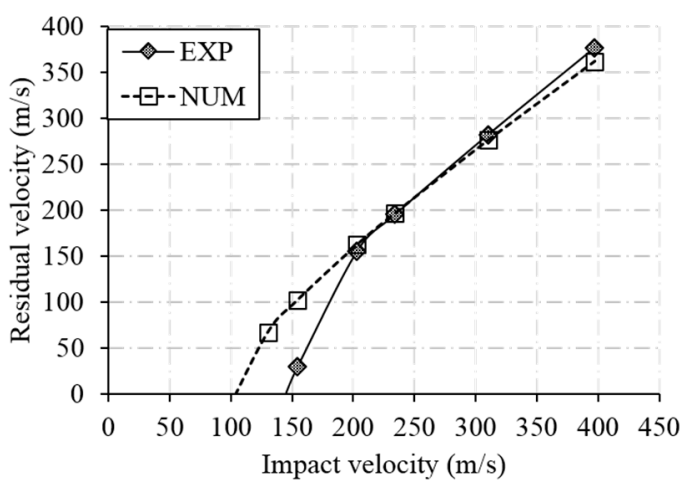

(a)

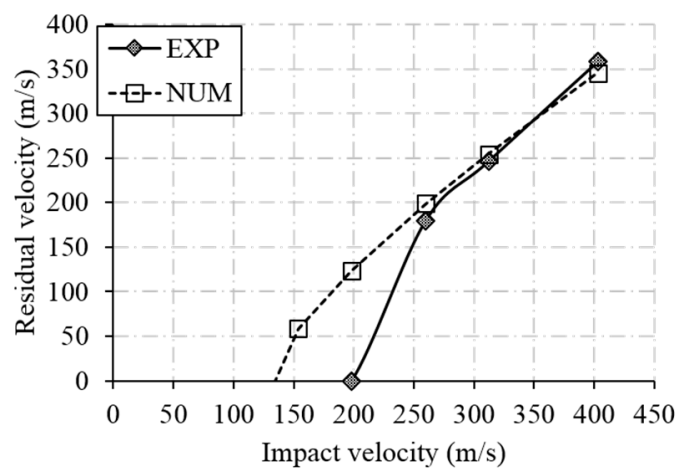

(b)

Figure 3. Variation of the projectile residual velocity for different impact velocity. (a) TFML-2/1 panel; (b) TFML-3/2.

Table 4. Impact velocity and corresponding residual velocity magnitude.

\begin{tabular}{|c|c|c|c|c|c|c|c|}
\hline \multirow{3}{*}{ Sample } & \multirow{3}{*}{$V_{i}(\mathrm{~m} / \mathrm{s})$} & \multicolumn{2}{|c|}{$V_{r}(\mathrm{~m} / \mathrm{s})$} & \multicolumn{4}{|c|}{ Dimensionless Parameters } \\
\hline & & \multirow{2}{*}{ EXP } & \multirow{2}{*}{ NUM } & \multicolumn{2}{|c|}{$\alpha$} & \multicolumn{2}{|c|}{$\beta$} \\
\hline & & & & EXP & NUM & EXP & NUM \\
\hline \multirow{6}{*}{ TFML-2/1 } & 130 & -36.8 & 66.91 & \multirow{6}{*}{1.008} & \multirow{6}{*}{0.978} & \multirow{6}{*}{2.255} & \multirow{6}{*}{1.725} \\
\hline & 154 & 29 & 101.8 & & & & \\
\hline & 203 & 155.6 & 162.6 & & & & \\
\hline & 234 & 195.5 & 197 & & & & \\
\hline & 310 & 282.3 & 276.5 & & & & \\
\hline & 397 & 376.9 & 362.5 & & & & \\
\hline \multirow{5}{*}{ TFML-3/2 } & 154 & -31.3 & 58.27 & \multirow{5}{*}{0.986} & \multirow{5}{*}{0.920} & \multirow{5}{*}{2.190} & \multirow{5}{*}{1.932} \\
\hline & 198 & 0 & 123.2 & & & & \\
\hline & 260 & 180 & 198.9 & & & & \\
\hline & 312 & 246 & 254.4 & & & & \\
\hline & 403 & 357.8 & 345.1 & & & & \\
\hline
\end{tabular}

At a lower impact velocity range, the numerically predicted $V_{r}$ was found to be larger than the experimental magnitude. However, such a difference was approaching smaller at a higher impact velocity range. At a lower impact velocity range, the fragments of perforated front layers were still in contact with the target hold by the petals of the bottom metal layers. Such scenarios might increase the perforation resistance of TFML and cause a smaller magnitude in the experimental study. However, the imposed precautionary simplification in the numerical model to avoid earlier abortion because of excessive element distortion that was caused by localized large deformation might be the reason for such initial under-prediction. Instantaneous damage evolution, which controls the element deletion, was defined with zero magnitude for fracture energy. This assumption validate correlates extremely well for high impact velocities, since the perforation at these velocities is extremely instantaneous. Moreover, the negligence of the rolling effect of the metal layer and the assumption of perfect circular target plate boundary with no slippage might also influence the conservative prediction of the numerical model in the lower impact velocity range. As observed in the experiments, the measured primary material properties are too sensitive to the rolling direction. Moreover, even 
though the TFML target panels are clamped firmly with a proper fixture, the post observation of the target surface ensures that there exists a slippage which might relax the panel to bend and, in turn, enhance the perforation resistance.

The amount of energy transferred to the target from projectile, $E_{t}^{p}$ was determined by substituting the predicted $V_{r}$ to Equation (4) given in [37];

$$
E_{t}^{p}=\frac{1}{2} m_{p}\left(V_{i}^{2}-V_{r}^{2}\right)
$$

Knowing $E_{t}^{p}$, the change in the projectile kinetic energy (incident impact energy), $E_{k}^{p}$ because of energy transfer can be found by dividing $E_{t}^{p}$ to $E_{k}^{p}$ as given in Equation (5);

$$
\frac{E_{t}^{p}}{E_{k}^{p}}=\frac{\frac{1}{2} m_{p}\left(V_{i}^{2}-V_{r}^{2}\right)}{\frac{1}{2} m_{p} V_{i}^{2}}
$$

Figure 4 shows the variation of projectile kinetic energy of the TFML-2/1 and TFML-3/2 panel with respect to their corresponding impact energy that was predicted from numerical simulation. Both of the TFML configurations exhibited an exponential decay of energy ratio with an increase in impact energy. As expected, the energy transferred in the TFML-3/2 panel is larger than that in the TFML-2/1 panel because of the larger thickness that was provided by the additional metal/composite layers. Observation of a similar sort of variation and constant energy change difference between the TFML-2/1 and 3/2 samples signifies that the stacking configuration does not alter the nature of the energy absorbing behavior over the range of the incident impact energy on the considered TFML panels.

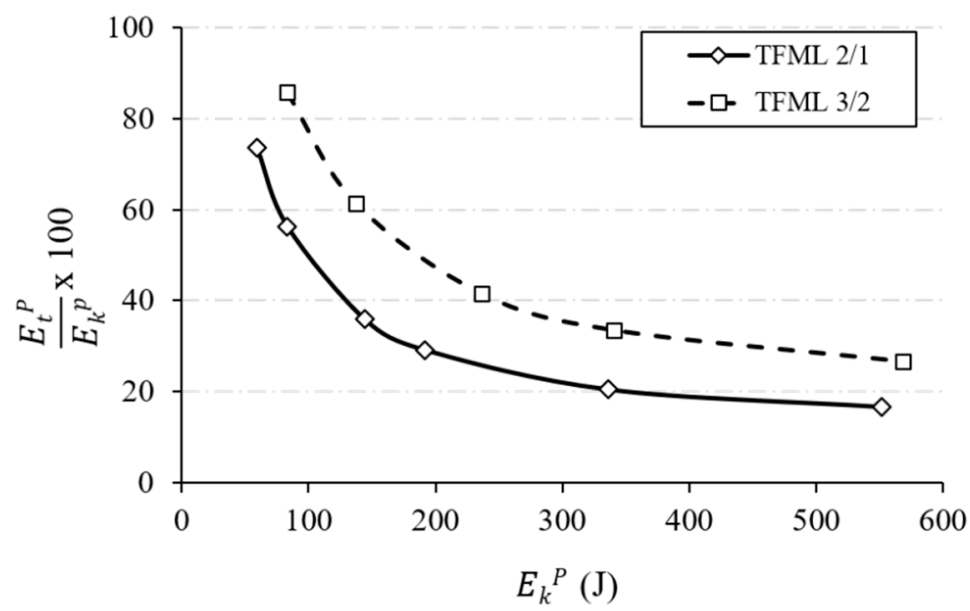

Figure 4. Effect of the TFML stacking configuration on projectile kinetic energy change for the range of incident impact energy.

\subsection{Contact History}

Figure 5 shows the contact force history of the TFML-2/1 sample with respect to contact time for different impact velocities. A similar response has also been observed for the TFML-3/2 sample case. At a low impact velocity range, the force variation looks smooth and no apparent peak exists on both of the sample configurations; while at a higher impact velocity range, the force history had a pulsating response with a series of abrupt load drops. The amplitude of the force peaks and the pulsation excitation were grown larger with an increase in impact velocity. Higher order vibrations that were excited due to sudden stress shock waves that were caused by high velocity impact might be the primary source for such oscillatory force response behavior. 


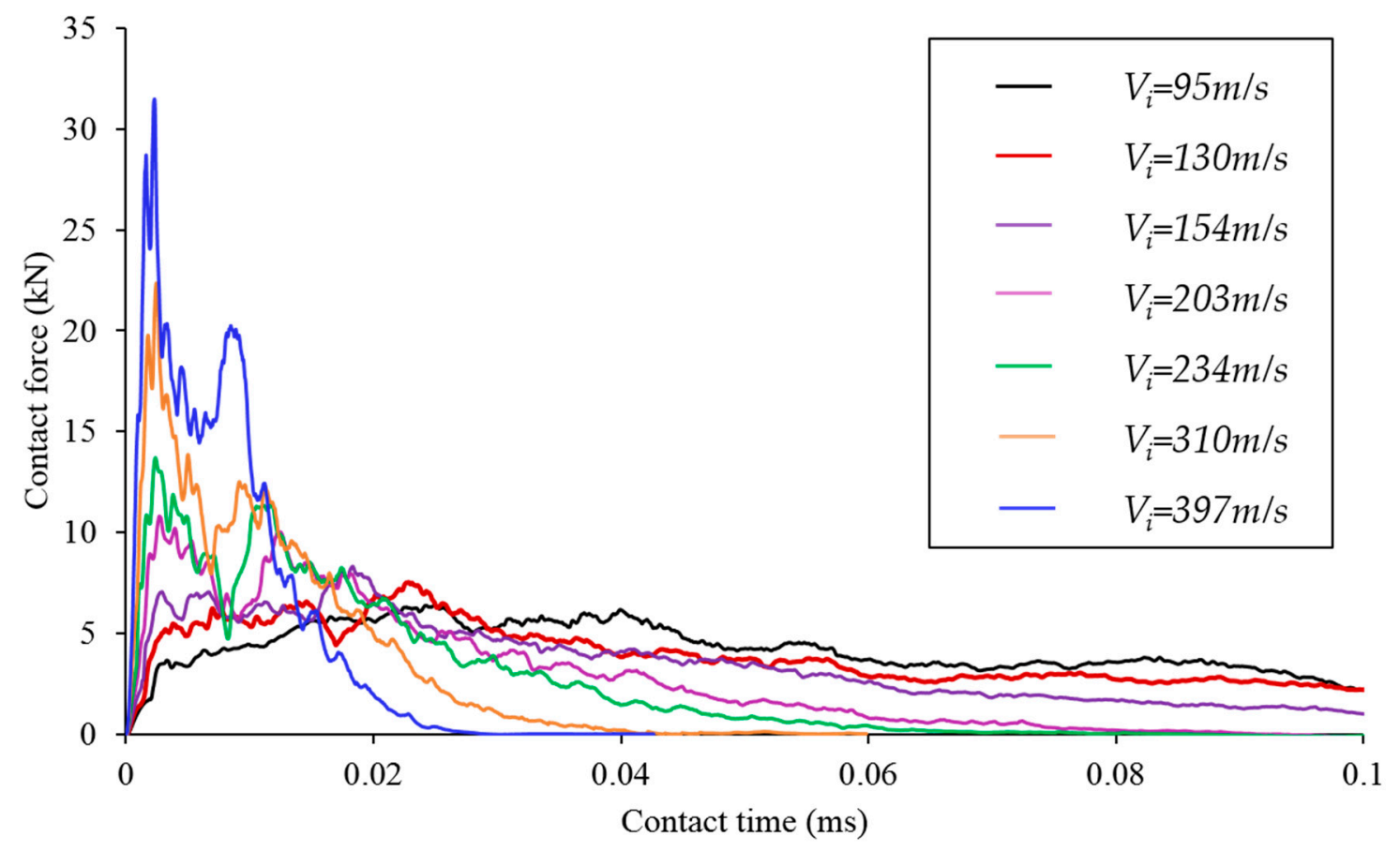

Figure 5. Contact force history of the TFML-2/1 target panel at different impact velocity.

Figure 5 shows that the absolute peak force increases with increasing impact velocity. It also shows that the time required to completely perforate the TFML laminate (i.e., contact force decreases to zero) decreases with increasing impact velocities. In the context of impact dynamics, contact time is defined as the total time of contact interaction that was present between the projectile and target panel. For the case of ballistic impact $\left(V_{i}>V_{b}\right)$, the above definition can be redefined as the time taken by the projectile to completely perforate the target and is termed perforation resistance. The magnitude of contact time is extremely important since it defines the level of resistibility that is provided by the target to avoid perforation. Figure 6 presents the variation of the contact time to the incident kinetic energy range that is simulated. As it can be seen, TFML targets of different stacking configuration $(2 / 1$ vs. $3 / 2)$ and thickness $(1.8 \mathrm{~mm}$ vs. $3.16 \mathrm{~mm})$ influence the contact time which attributes to the geometry parameters which have a negligible influence after ballistic limit. For both of the TFML sample cases, the perforation resistance observed decreases with increasing impact energy.

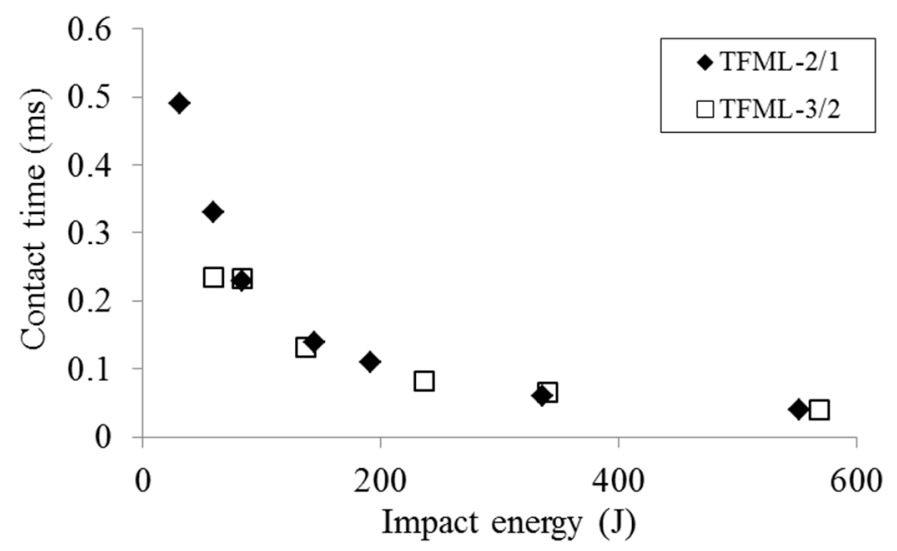

Figure 6. Contact force history of TFML panels at different impact velocity.

\subsection{Energy Dissipation}

Under localized transverse ballistic load conditions, FML panels dissipate the incident impact kinetic energy by the following forms in general [38]: 
- Undergo global and local plastic deformation.

- Creating different fibre/matrix failure modes of composite layers.

- Forming petaling fracture and bending of petals on the bottom metal surface.

- Shear plugging on top of the impacted metal surface.

Energy dissipation in the form of heat, vibration and interlaminar/interface damage are minor, and their proportion is negligibly small compared to the overall absorbed energy. Amongst it all, the energy dissipation in the form of plastic deformation of the metal layer is relatively dominant compared to the other dissipation forms. Figure 7 shows the variation of the total internal energy absorbed by the TFML panel and the plastic energy absorbed by the titanium layers. The percentage of both energy magnitudes are found to continuously increase with increases in impact kinetic energy. The presence of an additional metal layer allows the TFML-3/2 target to absorb more energy than the TFML-2/1 panel that has only two metal layers.

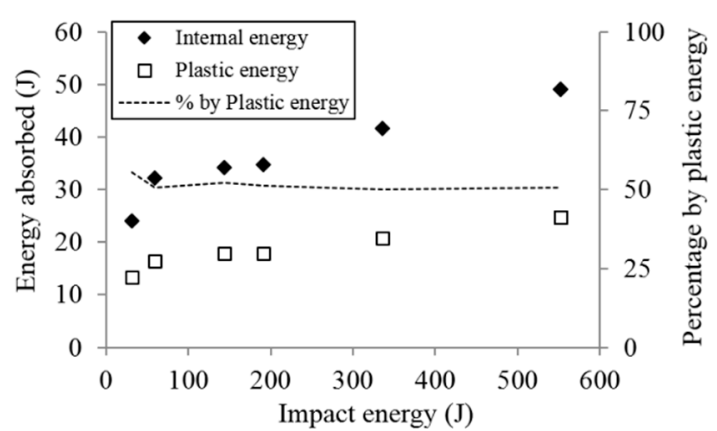

(a)

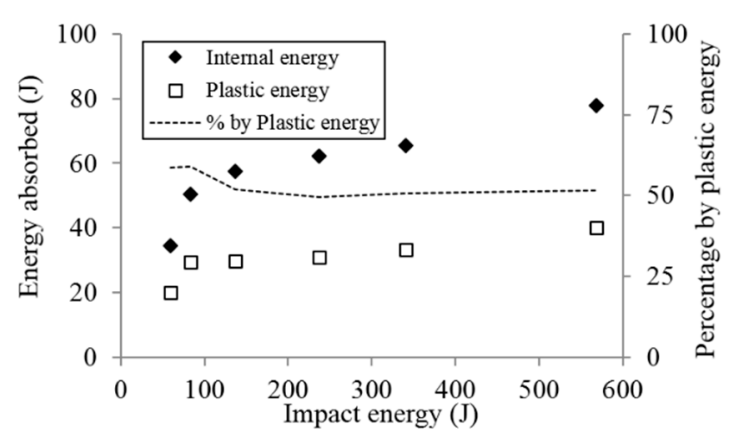

(b)

Figure 7. Energy absorption by the TFML panels at different impact energy. (a) TFML-2/1; (b) TFML-3/2.

In the interply fashion of hybridization which has a brittle and ductile material layer like FML, the level of plastic flow in the ductile layer depends on the fraction of deformation resistance that is provided by the adjacent brittle layer. In the considered TFML configurations, the volume fraction of metal to whole laminate, so called metal volume fraction (MVF) is approximately constant, as listed in Table 1. This fact reflects in the magnitude of plastic energy that is dissipated by the titanium layers on both samples. As seen in Figure 7, the relative percentage of plastic energy to total energy absorbed was found to be constant for about $50 \%$ of the tested impact energy range.

\subsection{Damage Morphology}

Figure 8 illustrates the numerically predicted laminate and layer-wise perforated damage shapes of the TFML 3/2 panels, respectively. Complete perforation caused by circular projectile creates a dome shape petaling crack on the backside titanium layer, while the front side titanium layer undergoes severe localized plugging failure [39]. Having balanced the orthotropic CFRP material property definition, axisymmetric loading and boundary conditions, the damaged surfaces of every layer in the laminate is doubly symmetrical in nature. Analyzing from the front to the back layer of the laminate, the damaged area of the titanium and CFRP composite layers gradually increases. The cross-sectional view explores the inverse pine tree pattern of damage evolution-a characteristic damage pattern for thin layered panels that are subjected to impact loads [40]. 


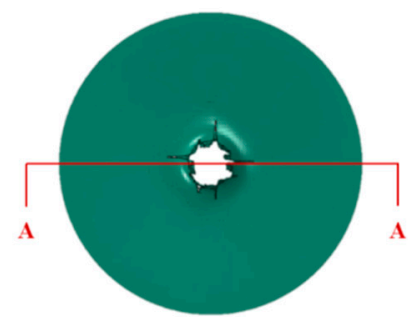

Back view

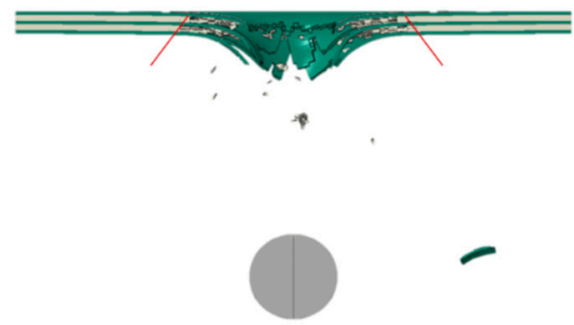

Cross sectional view

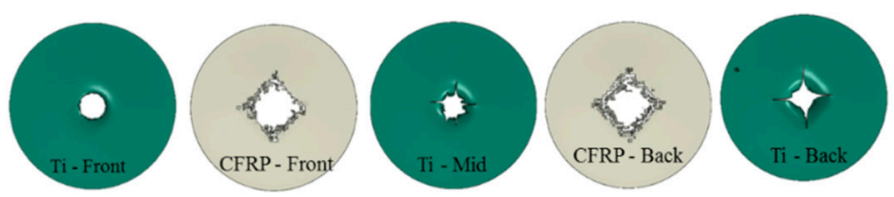

Layer wise view

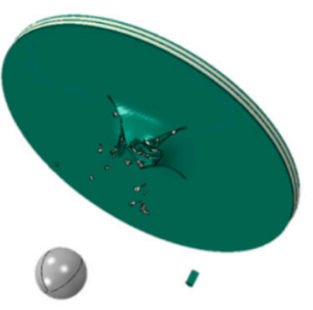

Isometric view

Figure 8. Laminate and layer wise damage shapes of the TFML-3/2.

Figure 9 illustrates the cross-sectional damage of the TFML $3 / 2$ panels at different stages of perforation when impact is at $403 \mathrm{~m} / \mathrm{s}$. The perforation resistance of each material layer on an interply hybrid laminate is inherently dependent on the level of failure interaction between distinct adjacent material layers to overall local/global laminate deformation. As observed, the perforation in TFML is layer-wise progressive in nature. The strong interaction of different levels of deformation $\left(\delta_{i}\right)$ to different failure surface nucleation is highly evident while investigating the damage evolution at different contact times $\left(t_{\mathrm{c}}\right)$.

The order of damage progression and failure of material layers on the TFML-3/2 panel are as follows:

i. Compressive contact pressure due to the projectile impact causes localized dent deformation under the contact area. (Figure 9b)

ii. Damage occurs in CFRP composite layers caused by matrix cracking and fibre fracture failure modes. The damage originates first in the top CFRP layer and then spreads to the bottom layer at higher displacement of the projectile. (Figure 9b,c)

iii. Fracture in the titanium layer occurs first at the bottom side and soon after the other metal layers are instantaneously fractured. The state of damage at this stage is termed as "complete penetration" denoting that damage occurs to all layers in the TFML panel. (Figure 9d)

iv. The projectile perforated through damaged layers of the laminate postulated here as "partial perforation" where the projectile does not eject and still holds contact with the completely penetrated target. (Figure 9e)

v. Finally, the "complete perforation" stage is reached, where the projectile completely lost its contact with the target and continues at constant residual velocity $\left(V_{r}\right)$. At this point, the contact force that is resisted by the target reads zero. (Figure 9f) 


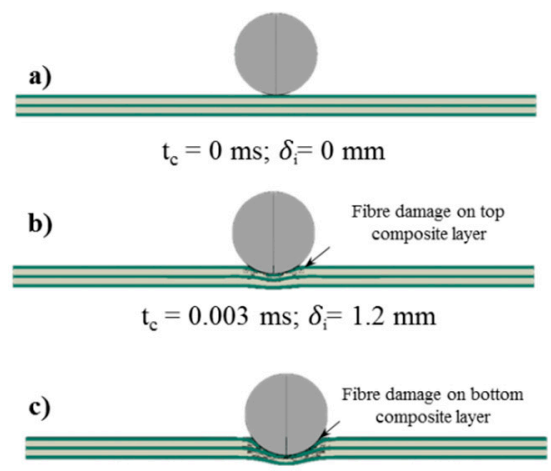

$\mathrm{t}_{\mathrm{c}}=0.0068 \mathrm{~ms} ; \delta_{\mathrm{i}}=2.6 \mathrm{~mm}$

d)

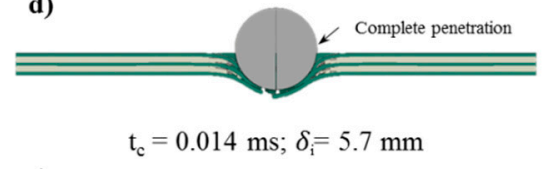

e)

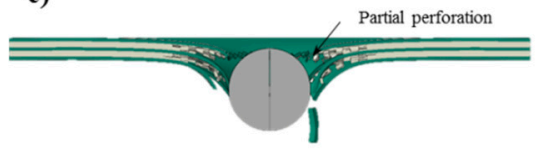

$\mathrm{t}_{\mathrm{c}}=0.032 \mathrm{~ms} ; \delta_{\mathrm{i}}=13.5 \mathrm{~mm}$

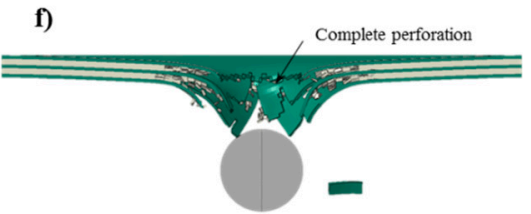

$\mathrm{t}_{\mathrm{c}}=0.065 \mathrm{~ms} ; \delta_{\mathrm{i}}=22.8 \mathrm{~mm}$
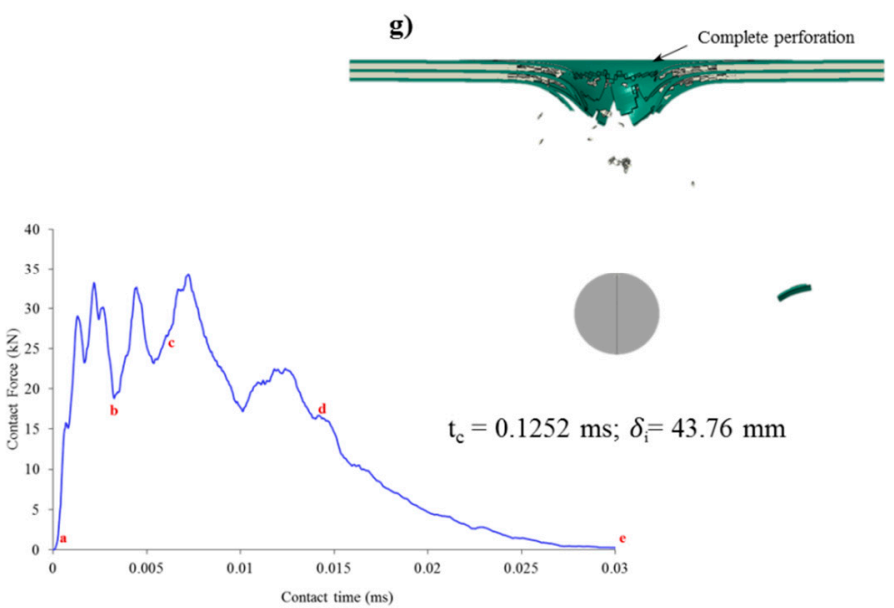

Figure 9. Damage progression in the TFML-3/2 target impacted at $403 \mathrm{~m} / \mathrm{s}$.

The failure progression of TFML-2/1 also develops a similar damage scenario where the middle CFRP layer fails first, followed by the bottom and top metal layers showing petaling failure on the backside and plugging failure on the front. Figure 10 illustrates the observed experimental and numerical plugging and petaling damage surface of the front and back sides of the metal layer of TFML, respectively. The close observation of the cross sectional damage surface in Figure $9 \mathrm{~d}-\mathrm{f}$ shows that the plan area of the damaged surface that was found expanded during projectile perforation. As a result, the final damage locus that nucleated on every material layer is found to expand over a larger area than the maximum contact area as shown for the TFML-2/1 sample in Figure 11. Good correlation between experimental and numerical predicted damage surfaces confirms the validity of the finite element model to produce all of the observed damaged surfaces.

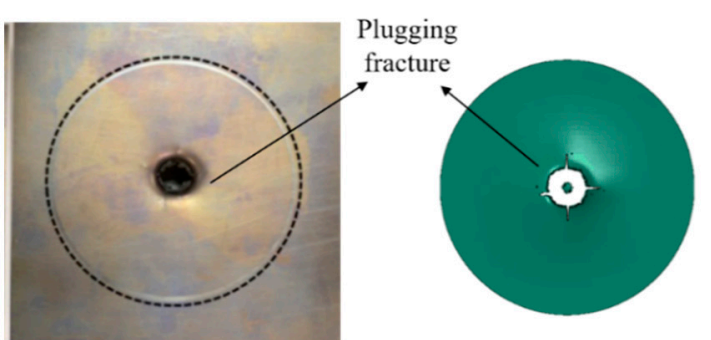

(a) Front metal layer

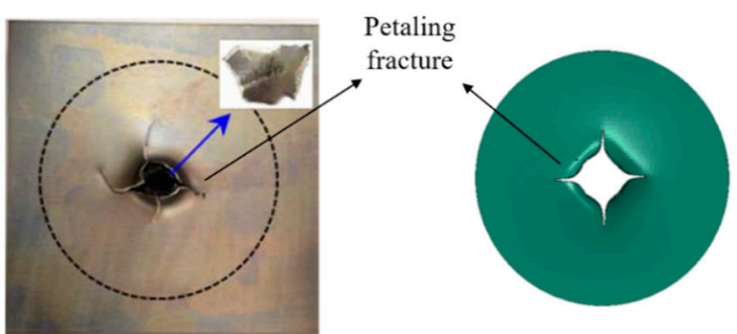

(b) Back metal layer

Figure 10. Perforated damage surface of the Titanium layer. 


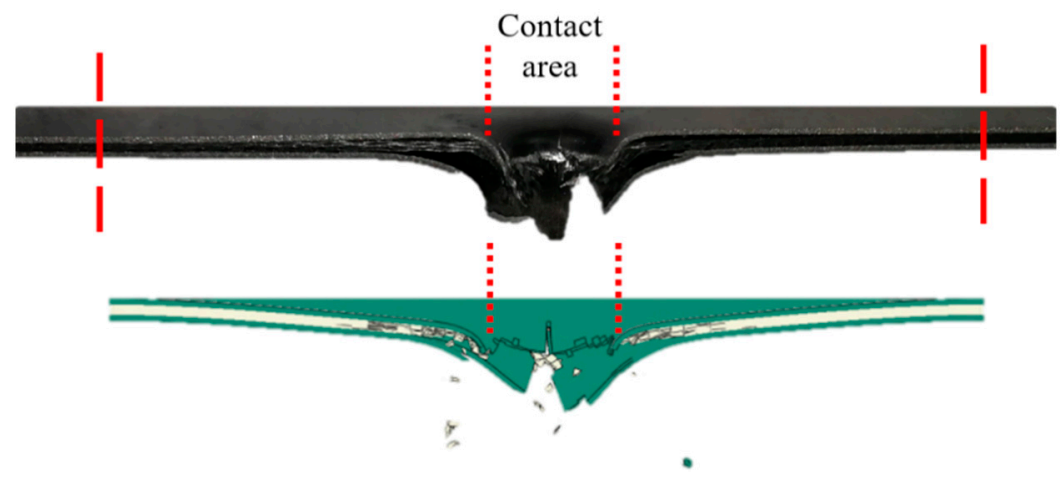

Figure 11. Cross sectional damage surface of the TFML-2/1.

The numerically predicted fibre/matrix failure locus of the CFRP layers on the TFML- $3 / 2$ target is shown in Figure 12. Both constituent failure modes are symmetric along the warp (global X-axis) and weft (global Y-axis) directions. The damage shape of the matrix failure emerges as rhombus in shape where the major and minor axes are coincident with the global laminate axes $X$ and $Y$, respectively. The fibre failure resembles a peanut in shape, where the fibre damage is larger around the peripheral region of the projectile maximum contact area. For all the simulated impact velocity range, the damage area of both fibre and matrix failure modes are larger than the maximum contact area (shown as a white solid line). Furthermore, the larger bending deformation and tensile stress field causes larger damage to the CFRP layer that lies closer to the back side than the front side of the CFRP layer. In view of impact velocity influence, the matrix failure locus extends almost the same size whilst the fibre failure notably increases with increases in the projectile impact velocity. On comparing the damage locus of the CFRP layers with their adjacent titanium layers, the latter has a smaller damage area than the former because the titanium layer undergoes severe localized deformation under its contact area.

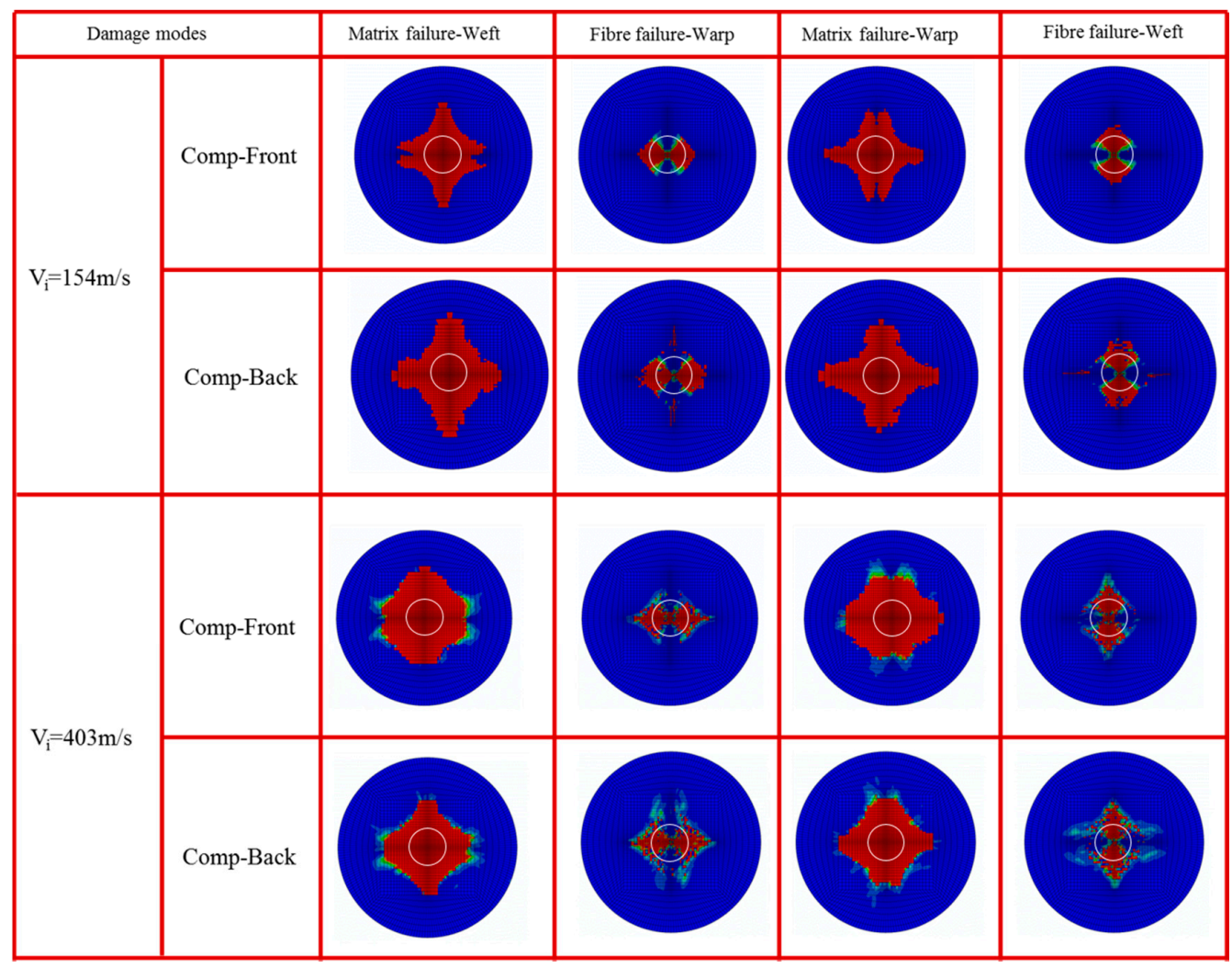

Figure 12. Fibre and matrix failure mode shape of the TFML $3 / 2$ target. 
One major advantage of FML being used for ballistic protection is the presence of an outer ductile metal layer which acts like a blockade and arrests the expulsion of broken CFRP fragments, which, in turn, protects the structure that is present behind the TFML target from multiple small impacts.

\section{Concluding Remarks}

A finite element model of titanium-based fibre metal laminate (TFML) panel that was subjected to high velocity impact by a rigid spherical steel projectile was presented. Flat TFML panels of two configurations; $1.85 \mathrm{~mm}$ thick $2 / 1$ and $3.2 \mathrm{~mm}$ thick $3 / 2$ targets were impacted with velocities ranging from $90 \mathrm{~m} / \mathrm{s}$ to $400 \mathrm{~m} / \mathrm{s}$. The behavior of the TFML laminate was captured through defining an appropriate independent constitutive material model for the titanium layer and the plain weave CFRP layer. Output variables like projectile residual velocity, kinetic energy change, contact force history, contact time variation, layer and laminate level damage morphology were derived and were investigated. The main conclusions extracted from this study are summarized as follows.

Correlation of the predicted residual velocities with the experimental measured velocities showed that the predicted values were under predicted for the lower impact velocity range, however showed close agreement for the higher impact velocity range. Implementing progressive damage evolution formulation and considering the interlaminar delamination modelling in future may mitigate the difference of residual velocities at smaller velocity impact conditions.

- Adding an additional layer of Titanium and a CFRP layer to create TFML-3/2 from 2/1 increases the weight of the target by $58 \%$. The larger thickness of TFML-3/2 increased the ballistic limit velocity by $32 \%$ (by experiment) and $37 \%$ (by numerical) compared to TFML- $2 / 1$.

- The perforation resistance of the TFML panels were dictated by change in the projectile kinetic energy $\left(E_{t}^{p} / E_{k}^{p}\right)$, and the total contact time shows exponential decay with increases in impact energy.

- The plot of contact history shows that the peak contact load increases with increases in impact velocity, even after the ballistic limit state.

- Having similar metal volume fraction (MVF), the percentage of energy that was absorbed by plastic deformation of the Titanium layers was found to be constant (approximately 50\%) for the TFML 2/1 and 3/2 panels, even though their geometric thickness was different.

- At all of the impact velocity range, the damage area in the perforated TFML panels was always larger than the maximum projectile contact area, both in layer wise and at the laminate level. The top metal layer showed a plugging type of failure while the bottom metal layer formed a petaling kind of failure with a visible dome shaped damage surface. Fibre and matrix failure modes of the woven composite layers were symmetric in shape because of its balanced material property, whereas the former had peanut and the latter had rhombus shaped damage surfaces.

Author Contributions: Conceptualization, G.B.C., P.M., and X.L.; Experiments, X.L.; Numerical, P.M., and G.B.C.; Writing-Original Draft Preparation, P.M.; Writing-Review \& Editing, Supervision-Project Administration \& Funding Acquisition, G.B.C.

Funding: This work was supported by DIRP Grant (No. 9013103595) from DRTech@MINDEF of Singapore and the National Natural Science Foundation of China (Grant No. 11402163).

Acknowledgments: The authors would like to thank Yang Jinglei (Hong Kong University of Science and Technology) for his valuable suggestions and contributions in the discussion.

Conflicts of Interest: The authors declare no conflicts of interest. 


\section{Appendix A. Material Model Used for Metal Layer}

The initial hydrodynamic (volumetric) behaviour of the thin metal layer is described by the Mie-Gruneisen equation of state (EOS) given as:

$$
p=\frac{\rho_{0} c_{0}^{2} \eta}{(1-s \eta)^{2}}\left(1-\frac{\Gamma_{0} \eta}{2}\right)+\Gamma_{0} \rho_{0} E_{m}
$$

where $\rho_{0}$ is the reference material density, $\Gamma_{0}$ is the material constant, $\eta$ is the nominal volumetric compression strain, $E_{m}$ is the internal energy per unit mass and $c_{0}$ and $\mathrm{s}$ are the constants relating linear shock velocity and particle velocity.

The elastic and plastic response of metal layers are defined by isotropic elasticity and Johnson cook (JC) plasticity, respectively. The latter accounts the effects of strain hardening, strain rate and thermal softening of the metal layer which are dominant during dynamic ballistic impact load case. The mathematical form of JC plasticity model is given as:

$$
\sigma_{y}=\left[A+B\left(\bar{\varepsilon}^{p}\right)^{n}\right]\left[1+\operatorname{Cln}\left(\dot{\varepsilon}^{*}\right)\right]\left[1+\left(T^{*}\right)^{m}\right]
$$

where the parameters $A, B$ and $n$ represents yield stress, hardening constant and hardening exponent, respectively. Strain rate dependence is controlled by the constant $C$ and non-dimensional strain rate $\dot{\varepsilon}^{*}$ Thermal dependency of the material is accounted by a non-dimensional temperature $T^{*}$ and thermal softening co-efficient, $m$.

The failure initiation of the metal layer is described by the Johnson Cook dynamic failure model. The failure criteria is a function of five dimensionless parameters $\left(d_{1}, \ldots, d_{5}\right)$ of the form:

$$
\bar{\varepsilon}_{f}^{p l}=\left[d_{1}+d_{2} \exp \left(d_{3} \frac{p}{q}\right)\right]\left[1+d_{4} \ln \left(\dot{\varepsilon}^{*}\right)\right]\left[1+d_{5} T^{*}\right]
$$

where $\frac{p}{q}$ is the stress triaxiality parameter. The value of failure parameters $\left(d_{1}, \ldots, d_{5}\right)$ is determined through a series of fracture experiments by varying stress triaxiality, strain rate and temperature.

\section{Appendix B. Material Model Used for Plain Weave Composite Layer}

\section{Appendix B.1. Overview of Multi-Continuum Theory (MCT)}

Multi-continuum theory (MCT), a micromechanics-based failure theory, is used to predict failure of a material made of more than one material constituent. Failure prediction is based on homogenized (average) stress of a continuum determined from stress fields of constituent materials. For a fibre reinforced composite continuum region $D$ of volume $V$, plain weave pattern of composites contain three constituents; fill (weft) fibre bundles, warp fibre bundles and pure matrix pockets as shown by means of representative volume element (RVE) in Figure A1. 


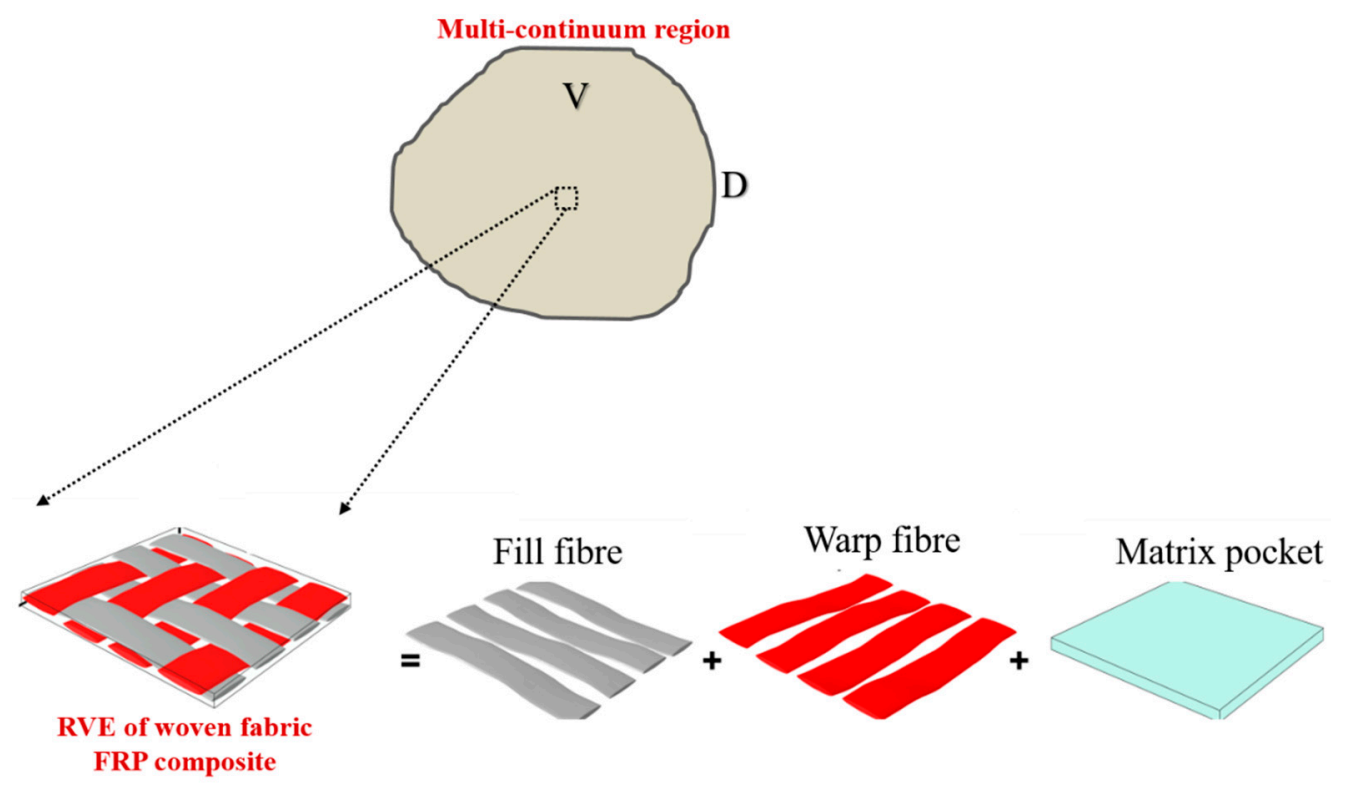

Figure A1. Woven composite material RVE definition in Multi Continuum Theory.

The homogenized stress tensor $\widetilde{\sigma}^{c}$ at any arbitrary continuum point in the given region ' $D$ ' is given by the volume average of stress tensor $\widetilde{\sigma}(x, y, z)$ as,

$$
\widetilde{\sigma}^{c}=\frac{1}{V} \int_{D} \widetilde{\sigma}(x, y, z) d V
$$

A similar form can be derived at constituent level (fill fibre (f), warp fibre (w) and pure matrix pockets (m)) as,

$$
\widetilde{\sigma}^{i}=\frac{1}{V_{i}} \int_{D_{i}} \widetilde{\sigma}(x, y, z) d V
$$

where $i=\{f, w, m\}$ and $D_{i}$ is the region containing each constituent in the $\operatorname{RVE}\left(D=D_{f} \cup D_{w} \cup D_{m}\right)$, and $V$ is the total volume of $\operatorname{RVE}\left(V=\sum V_{i}\right)$.

On combining Equations (A4) and (A5), the expression relating the composite and the constituent stress fields can be written in the form:

$$
\widetilde{\sigma}^{c}=\sum \varphi_{i} \widetilde{\sigma}^{i}
$$

where $\varphi_{i}=\frac{V_{i}}{V}$ is the volume fraction of each material constituent in the RVE.

Likewise, the relation for the homogenized strain tensor between composite $\left(\widetilde{\varepsilon}^{c}\right)$ and its constituent $\left(\widetilde{\varepsilon}^{i}\right)$ in the RVE is expressed as

$$
\widetilde{\varepsilon}^{c}=\sum \varphi_{i} \tilde{\varepsilon}^{i}
$$

Knowing the homogenized stress and strain tensors, the constitutive relation representing the elastic behavior of RVE is expressed as:

$$
\left\{\sigma^{c}\right\}=\left[C^{c}\right]\left\{\varepsilon^{c}\right\}
$$

Similarly, the elastic relation of each constituents is expressed as

$$
\left\{\sigma^{i}\right\}=\left[C^{i}\right]\left\{\varepsilon^{i}\right\}
$$

where $\left[C^{c}\right]$ and $\left[C^{i}\right]$ denotes stiffness matrices of composite and its constituents, respectively. Using Equations (A6)-(A9), phase averaged constituent stress and strains can be calculated at any continuum point from the known composite strain. 


\section{Appendix B.2. MCT Failure Criteria}

The constituent level average stress and strain in the MCT algorithm facilitates the numerical simulation to make significant enhancements in the prediction of failure and material degradation for woven fibre-reinforced composites [26,27]. Assuming that the degree of undulation in woven fabric bundles is negligible, the bundles are locally treated as transversely isotropic material.

\section{Appendix B.2.1. Matrix Failure Criteria}

The matrix failure criteria contains three adjustable coefficients $A_{i}^{m}$ and three invariant quantities $I_{i}^{m}$ in quadratic combination as follows:

$$
A_{1}^{m}\left\langle I_{1}^{m}\right\rangle^{2}+A_{2}^{m} I_{2}^{m}+A_{3}^{m} I_{3}^{m}=1
$$

where \langle\rangle denotes Macaulay operator to allow only tensile and shear stresses combination to induce failure but no compressive stress. The adjustable coefficients $A_{i}^{m}$ are evaluated from the measured strength of woven composite material. The explicit formulation of each invariant term of $I_{i}^{m}$ in Equation (A10) is given as:

$$
\begin{gathered}
I_{1}^{m}=\frac{1}{2}\left[\sigma_{22}^{m}+\sigma_{33}^{m}+\sqrt{\left(\sigma_{22}^{m}+\sigma_{33}^{m}\right)^{2}-4\left(\sigma_{22}^{m} \sigma_{33}^{m}+\left(\sigma_{23}^{m}\right)^{2}\right)}\right] \\
I_{2}^{m}=\left(\sigma_{12}^{m}\right)^{2}+\left(\sigma_{13}^{m}\right)^{2} \\
I_{3}^{m}=\frac{1}{4}\left[\left(\sigma_{22}^{m}-\sigma_{33}^{m}\right)^{2}+\left(\sigma_{23}^{m}\right)^{2}\right]
\end{gathered}
$$

Appendix B.2.2. Fibre Failure Criterion

The quadratic failure criterion based on the work of Mayes [41] is selected to simulate the fibre failure. The relation defining fibre failure takes the form:

$$
\pm A_{1}^{f}\left(I_{1}^{f}\right)^{2}+A_{2}^{f} I_{2}^{f}=1
$$

where coefficients $I_{i}^{f}$ are transversely isotropic invariants of homogenized fibre stress state given by:

$$
\begin{gathered}
I_{1}^{f}=\sigma_{11}^{f} \\
I_{2}^{f}=\left(\sigma_{12}^{f}\right)^{2}+\left(\sigma_{13}^{f}\right)^{2}
\end{gathered}
$$

where the adjustable coefficients $A_{i}^{f}$ are determined from the measured strength of woven composite material. The values are depending on the associated average stresses of matrix and fiber and the symbol \pm indicated whether the average stress is tensile or compressive. All of the above-introduced adjustable and invariant coefficients are automatically calculated during the solution step. The indication of fiber and matrix failure criteria is tracked through a separate state defined variable definition.

\section{References}

1. Navarro, C.; Martinez, M.A.; Cortés, R.; Sánchez-Gálvez, V. Some observations on the normal impact on ceramic faced armours backed by composite plates. Int. J. Impact Eng. 1993, 13, 145-156. [CrossRef]

2. Van der Werff, H.; Heisserer, U. 3 - High-performance ballistic fibers: Ultra-high molecular weight polyethylene (UHMWPE). In Advanced Fibrous Composite Materials for Ballistic Protection; Woodhead Publishing: Cambridge, UK, 2016; pp. 71-107. 
3. Vlot, A.; Gunnink, J.W. Fibre Metal Laminates: An Introduction; Kluwer Academic Publishers: Berlin/Heidelberg, Germany, 2001.

4. Vlot, A. Impact loading on fibre metal laminates. Int. J. Impact Eng. 1996, 18, 291-307. [CrossRef]

5. Morinière, F.D.; Alderliesten, R.C.; Benedictus, R. Modelling of impact damage and dynamics in fibre-metal laminates-A review. Int. J. Impact Eng. 2014, 67, 27-38. [CrossRef]

6. Hoo Fatt, M.S.; Lin, C.; Duane, M.R.; Dale Hopkins, A. Ballistic impact of GLARETM fiber-metal laminates. Compos. Struct. 2003, 61, 73-88. [CrossRef]

7. Compston, P.; Cantwell, W.J.; Jones, C.; Jones, N. Impact perforation resistance and fracture mechanisms of a thermoplastic based fiber-metal laminate. J. Mater. Sci. Lett. 2001, 20, 597-599. [CrossRef]

8. Langdon, G.S.; Cantwell, W.J.; Nurick, G.N. The blast response of novel thermoplastic-based fibre-metal laminates-Some preliminary results and observations. Compos. Sci. Technol. 2005, 65, 861-872. [CrossRef]

9. Vo, T.P.; Guan, Z.W.; Cantwell, W.J.; Schleyer, G.K. Low-impulse blast behaviour of fibre-metal laminates. Compos. Struct. 2012, 94, 954-965. [CrossRef]

10. Vo, T.P.; Guan, Z.W.; Cantwell, W.J.; Schleyer, G.K. Modelling of the low-impulse blast behaviour of fibre-metal laminates based on different aluminium alloys. Compos. Part B Eng. 2013, 44, 141-151. [CrossRef]

11. Cortés, P.; Cantwell, W.J. Interfacial fracture properties of carbon fiber reinforced PEEK/titanium fiber-metal laminates. J. Mater. Sci. Lett. 2002, 21, 1819-1823. [CrossRef]

12. Cortés, P.; Cantwell, W.J. The impact properties of high-temperature fiber-metal laminates. J. Compos. Mater. 2007, 41, 613-632. [CrossRef]

13. Boyer, R.R. Attributes, characteristics, and applications of titanium and its alloys. JOM 2010, 62, 21-24. [CrossRef]

14. Li, X.; Zhang, X.; Guo, Y.; Shim, V.P.W.; Yang, J.; Chai, G.B. Influence of fiber type on the impact response of titanium-based fiber-metal laminates. Int. J. Impact Eng. 2018, 114, 32-42. [CrossRef]

15. Yen, C.F. A ballistic material model for continuous-fiber reinforced composites. Int. J. Impact Eng. 2012, 46, 11-22. [CrossRef]

16. Silva, M.A.G.; Cismaşiu, C.; Chiorean, C.G. Numerical simulation of ballistic impact on composite laminates. Int. J. Impact Eng. 2005, 31, 289-306. [CrossRef]

17. Iqbal, M.A.; Tiwari, G.; Gupta, P.K.; Bhargava, P. Ballistic performance and energy absorption characteristics of thin aluminium plates. Int. J. Impact Eng. 2015, 77, 1-15. [CrossRef]

18. ABAQUS Technical Brief. Simulation of the Ballistic Perforation of Aluminum Plates with Abaqus/Explicit. Available online: https:/ / www.3ds.com/fileadmin/PRODUCTS-SERVICES/SIMULIA/RESOURCES/aeroballistic-perforation-alumnium-plates-12.pdf (accessed on 18 October 2018).

19. ABAQUS Technical Brief. Projectile Impact on a Carbon Fiber Reinforced Plate. Available online: https: / www.3ds.com/fileadmin/PRODUCTS-SERVICES/SIMULIA/RESOURCES / Aero-ProjectileImpact-on-a-Carbon-Fiber-Reinforced-06.pdf (accessed on 18 October 2018).

20. Pach, J.; Pyka, D.; Jamroziak, K.; Mayer, P. The experimental and numerical analysis of the ballistic resistance of polymer composites. Compos. Part B Eng. 2017, 113, 24-30. [CrossRef]

21. Reinhart, W.D.; Chhabildas, L.C.; Carroll, D.E.; Thornhill, T.G.; Winfree, N.A. Equation of State Measurements of Materials Using a Three-Stage Gun to Impact Velocities of $11 \mathrm{~km} / \mathrm{s}$. In Proceedings of the 7th Hypervelocity Impact Symposium (HIVS), Galveston, TX, USA, 6-10 November 2000.

22. Liaw, B.; Yaghoubi, A.S. Effect of lay-up orientation on ballistic impact behaviors of GLARE 5 FML beams. Int. J. Impact Eng. 2013, 54, 138-148.

23. Liaw, B.; Yaghoubi, A.S. Thickness influence on ballistic impact behaviors of GLARE 5 fiber-metal laminated beams: Experimental and numerical studies. Compos. Struct. 2012, 94, 2585-2598.

24. Soutis, C.; Mohamed, G.; Hodzic, A. Modelling the structural response of GLARE panels to blast load. Compos. Struct. 2011, 94, 267-276. [CrossRef]

25. Sitnikova, E.; Guan, Z.W.; Schleyer, G.K.; Cantwell, W.J. Modelling of perforation failure in fibre metal laminates subjected to high impulsive blast loading. Int. J. Solids Struct. 2014, 51, 3135-3146. [CrossRef]

26. Key, C.T.; Six, R.W.; Hansen, A.C. A three-constituent multicontinuum theory for woven fabric composite materials. Compos. Sci. Technol. 2003, 63, 1857-1864. [CrossRef]

27. Key, C.T.; Schumacher, S.C.; Hansen, A.C. Progressive failure modeling of woven fabric composite materials using multicontinuum theory. Compos. Part B Eng. 2007, 38, 247-257. [CrossRef] 
28. Kotzakolios, T.; Vlachos, D.E.; Kostopoulos, V. Blast response of metal composite laminate fuselage structures using finite element modelling. Compos. Struct. 2011, 93, 665-681. [CrossRef]

29. Nakatani, H.; Kosaka, T.; Osaka, K.; Sawada, Y. Damage characterization of titanium/GFRP hybrid laminates subjected to low-velocity impact. Compos. Part A Appl. Sci. Manuf. 2011, 42, 772-781. [CrossRef]

30. Kay, G. Failure Modeling of Titanium 6Al-4V and Aluminum 2024-T3 with the Johnson-Cook Material Model; DOT/FAA/AR-03/57; U.S. Department of Transportation: Washington, DC, USA, 2003.

31. Theory Manual: Autodesk simulation composite analysis 2015. Available online: http:/ / help.autodesk.com/ view/ACMPAN/2015/ENU/ (accessed on 22 October 2018).

32. Kerley, G.I. Equations of State for Titanium and Ti6A14V Alloy; SANDIA Report 3785; Sandia National Laboratories: Albuquerque, NM, USA, 2003.

33. Tennyson, R.C.; Wharram, G.E. Evaluation of Failure Criterion for Graphite/Epoxy Fabric Laminates; NASA Contract Report-172547. Available online: https:/ /ntrs.nasa.gov/archive/nasa/casi.ntrs.nasa.gov/ 19850010715.pdf (accessed on 18 October 2018).

34. Kaboglu, C.; Mohagheghian, I.; Zhou, J.; Guan, Z.; Cantwell, W.J.; John, S.; Blackman, B.R.K.; Kinloch, A.J.; Dear, J.P. High-velocity impact deformation and perforation of fibre metal laminates. J. Mater. Sci. 2018, 53, 4209-4228. [CrossRef]

35. Seo, H.; Hundley, J.; Hahn, H.T.; Yang, J.M. Numerical Simulation of Glass-Fiber-Reinforced Aluminum Laminates with Diverse Impact Damage. AIAA J. 2010, 48, 676-687. [CrossRef]

36. Recht, R.F.; Ipson, T.W. Ballistic Perforation Dynamics. J. Appl. Mech. 1963, 30, 384-390. [CrossRef]

37. Xie, W.; Zhang, W.; Kuang, N.; Li, D.; Huang, W.; Gao, Y.; Ren, P. Experimental investigation of normal and oblique impacts on CFRPs by high velocity steel sphere. Compos. Part B Eng. 2016, 99, 483-493. [CrossRef]

38. Lin, C.; Hoo Fatt, M.S. Perforation of Composite Plates and Sandwich Panels under Quasi-static and Projectile Loading. J. Compos. Mater. 2006, 40, 1801-1840. [CrossRef]

39. Corbett, G.G.; Reid, S.R.; Johnson, W. Impact loading of plates and shells by free-flying projectiles: A review. Int. J. Impact Eng. 1996, 18, 141-230. [CrossRef]

40. Abrate, S. Impact on Composite Structures; Cambridge University Press: Cambridge, UK, 1998.

41. Steven Mayes, A.; Hansen, C.J. Multicontinuum Failure Analysis of Composite Structural Laminates. Mech. Compos. Mater. Struct. 2001, 8, 249-262. [CrossRef] 